\title{
TECNOLOGIA E EDUCAÇÃO: ALGUMAS CONSIDERAÇÕES SOBRE O DISCURSO PEDAGÓGICO CONTEMPORÂNEO
}

\author{
JOANA PEIXOTO* \\ Cláudia Helena dos Santos Araújo*
}

\begin{abstract}
RESUMO: O presente artigo pretende analisar os fundamentos do discurso predominante sobre as relações entre as tecnologias e a educação, tomando por base um estado da arte realizado sobre os usos do computador na educação escolar, no período de 1997 a 2007 no Brasil. Nesse estado da arte foram encontrados 107 trabalhos relacionados a essa temática e a referência a 1.330 autores. A análise destes trabalhos conduz à reflexão que busca apoio teórico em um descolamento dos discursos habituais sobre o uso das tecnologias em educação: tanto aqueles que se baseiam nas prescrições normativas para a incorporação dos instrumentos tecnológicos (visão instrumental), como aqueles que impõem as TIC como uma fatalidade no seio das escolas (determinismo tecnológico). O corpus total foi objeto de análise de conteúdo, indicando as categorias: o computador como recurso didáticopedagógico e o computador como recurso político-pedagógico.
\end{abstract}

Palavras-chave: Computador. Educação escolar. Discurso pedagógico.

\section{TECHNOLOGY AND EDUCATION: SOME CONSIDERATIONS REGARDING THE CONTEMPORARY PEDAGOGICAL DISCOURSE}

ABSTRACT: This article intends to analyze the principles of the dominant discourse upon the relationship between technology and education based on a state-of-the-art of the computer use in school education from 1997 to 2007 in Brazil. During the research, 107 related works was found on this subject and also references 1330 authors. The analysis of these researches lead to a reflection that searches theoretical support in the displacement of customary discourses concerning the uses of technology in education: those based on the normative prescriptions that seek the incorporation of

* $\quad$ Doutora em Ciências da Educação e professora no Programa de Pós-Graduação em Educação da Universidade Católica de Goiás (UCG). E-mail: joanagynn@gmail.com

** Mestre em Educação e coordenadora de Projetos Pedagógicos e Tecnológicos da Diretoria de Ciência e Tecnologia, Secretaria Municipal de Educação, Ciência e Tecnologia de Anápolis (GO). E-mail: helena.claudia@gmail.com 
the technological tools (instrumentalist view) as well as those that impose the ICT (Information and Communication Technologies) as an inevitableness within the schools (determinist view). The whole corpus was used as object of content analysis, indicating the following categories: the computer as a pedagogical-didactic resource and the computer as a political pedagogical resource.

Key words: Computer. School education. Pedagogical discourse.

\section{TECHNOLOGIE ET ÉDUCATION: QUELQUES CONSIDÉRATIONS SUR LE DISCOURS PÉDAGOGIQUE CONTEMPORAIN}

RÉSUMÉ: Cet article se propose d'analyser les fondements du discours prédominant sur les relations entre les technologies et l'éducation, en prenant comme base un état des lieux réalisé sur l'utilisation des ordinateurs dans l'éducation scolaire, durant la période de 1997 à 2007 au Brésil. Dans cet état des lieux furent trouvés 107 travaux en lien avec cette thématique et la référence à 1330 auteurs. L'analyse de ces travaux conduit à une réflexion qui cherche un appui théorique dans la dissociation des discours habituels sur l'usage des technologies dans l'éducation: aussi bien ceux qui se fondent sur des prescriptions normatives pour l'incorporation des instruments technologiques (vision instrumentale) que ceux qui imposent les TIC comme une fatalité au sein des écoles (déterminisme technologique). Le corpus total a été l'objet d'une analyse de contenu, indiquant les catégories suivantes: l'ordinateur comme moyen didactico-pédagogique et l'ordinateur comme moyen politico-pédagogique.

Mots-clés: Ordinateur. Education scolaire. Discours pédagogique.

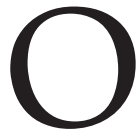

racionalismo moderno se articula em torno da ideia de que o humano - porque é dotado de razão - possui, por si mesmo, recursos necessários ao conhecimento do mundo e da moral. Por meio desta lógica, afirma-se a crença de que um conhecimento racional do funcionamento do mundo é possível e que a razão é capaz de definir, por si mesma, o bem e o mal. Ao invés de dever respeitar a uma vontade divina que lhe seria revelada ou a tradições que lhe seriam ensinadas pelos ancestrais, o homem se submeterá apenas às leis que ele propõe a si mesmo. A história da modernidade é, assim, a história da emancipação do homem da natureza e do divino como fundamento de todo conhecimento.

No plano físico, a realização deste ideal moderno se torna possível pela matematização do real. Ao exprimir matematicamente o conjunto dos fenômenos físicos, o homem se torna não apenas capaz de compreender estes fenômenos, mas também de prevê-los e dominá-los. Enquanto o homem antigo concebia o conhecimento do mundo como uma contemplação passiva de uma ordem natural à qual ele estava submisso, o homem moderno associa o conhecimento da natureza à capacidade de agir sobre ela e transformá-la. Desta forma, o conhecimento científico permite desenvolver um saber técnico graças ao qual o homem é, progressivamente, capaz de 
se libertar das contingências naturais. O homem se torna, segundo expressão de Descartes (1987), "mestre e senhor da natureza".

O que torna possível o progresso científico moderno é, então, a progressiva instauração de um referencial universal subjetivo, a razão humana. Esta valorização da razão humana sofre sérios abalos com diversas experiências da contemporaneidade, que exacerbam a exclusão social, põem em risco a vida no planeta e colocam a ética desta razão em questão, com os feitos da chamada tecnociência.

Assim, os riscos e os limites da razão humana, como referência universal e absoluta, demonstram os limites teóricos da racionalidade instrumental. Ressaltase o valor autônomo da técnica, a qual passa a ser vislumbrada como portadora de sentidos que seriam transmitidos e que configurariam a sociedade. Segundo esta concepção, o desenvolvimento social é determinado pelo desenvolvimento tecnológico e o desenvolvimento tecnológico é conduzido por uma lógica intrínseca ao seu próprio sistema (determinismo tecnológico).

Estas duas abordagens revelam, em parte, a dinâmica da visão contemporânea sobre a tecnologia. Observa-se um movimento que oscila entre a visão da tecnologia como uma ferramenta, ou meio flexível e adaptável ao uso imputado pelo homem, e a atribuição à tecnologia do poder de configurar a cultura e a sociedade. Tal dinâmica se reflete na apropriação da tecnologia pelo discurso e, consequentemente, pelas práticas pedagógicas.

A racionalidade instrumental inspira e dá fundamento aos projetos e experiências contemporâneos na integração das tecnologias ao processo educativo. Isto se revela nos discursos que abordam a integração das tecnologias à educação, baseando-se, preponderantemente, na visão da tecnologia como um meio para atingir finalidades pedagógicas. Nesta perspectiva, a tecnologia é pensada como mediação e como instrumento de transformação do processo de aprendizagem e das relações pedagógicas (Peixoto, 2007, 2008a).

Observa-se, por outro lado, estudos sobre a tecnologia na educação que se inserem numa lógica determinista, a qual tende a considerar que as tecnologias de informação e de comunicação (TIC) fazem surgir novos paradigmas ou perspectivas educativas (Sancho, 2006). Segundo esta abordagem, a tecnologia não é inteiramente controlada pelo homem (como se concebe numa visão instrumental); é ela que, utilizando-se do avanço do conhecimento do mundo natural, verdadeiro e neutro, molda (e empurra para um futuro cada vez melhor) a sociedade mediante as exigências de eficiência e progresso que estabelece.

Apesar destas constatações, a constituição do discurso pedagógico sobre os usos das tecnologias na educação ainda é algo recente. Os discursos acerca da educação 
atribuem lugar central às TIC, mas esta centralidade tem se baseado em justificativas e fundamentos tão diferentes que não é possível se realizar uma leitura singular deste quadro.

Este artigo pretende analisar os fundamentos do discurso predominante sobre as relações entre as tecnologias e a educação, tomando por base o estado da arte realizado sobre os usos do computador na educação escolar, no período de 1997 a 2007, nas produções científicas publicadas nos periódicos classificados como "Nacional e/ou Internacional nível A" no Qualis ${ }^{1}$ da Coordenação de Aperfeiçoamento de Pessoal de Nível Superior (Capes), ${ }^{2}$ bem como no grupo de trabalho sobre "Educação e Comunicação", da Associação Nacional de Pós-Graduação e Pesquisa em Educação (ANPEd). ${ }^{3}$

Nesse "estado da arte" foram encontrados 107 trabalhos relacionados a essa temática e 1.330 autores referenciados nesses estudos. A análise destes trabalhos conduz à reflexão que busca apoio teórico para a "des-familiarização" (Papadoudi, 1998, p. 24) dos discursos habituais sobre o uso das tecnologias em educação: tanto aqueles que se baseiam nas prescrições normativas para a incorporação dos instrumentos tecnológicos (visão instrumental), como aqueles que impõem as TIC como uma fatalidade no seio das escolas (determinismo tecnológico) (Peixoto, 2008b).

\section{Discursos pedagógicos sobre os usos do computador na educação escolar}

A produção científica sobre os usos do computador na educação escolar se fundamenta em diferentes pressupostos teóricos. Entende-se por orientação teórica do discurso pedagógico a teorização apresentada nos textos encontrados, que sustentam o discurso e as ideias acerca da Educação e Informática.

Foi realizada uma análise de conteúdo (Franco, 2005), cujas categorias analíticas agruparam temáticas evidenciadas nas ideias que emergiram dos textos. A partir da referida análise de conteúdo, observou-se a presença de duas grandes categorias no discurso pedagógico contemporâneo sobre os usos do computador na educação: "o computador como recurso didático-pedagógico" e "o computador como recurso político-pedagógico".

Para demonstrar a orientação teórica do discurso presente nos artigos científicos, tomou-se como um dos critérios a frequência na qual o autor é citado. Para tal, utilizou-se como referência os autores que se repetem em, pelo menos, nove dos textos da amostra trabalhada, indicados a seguir por frequência de citação: 1) Pierre Lévy; 2) Paulo Freire; 3) Lev Vigotski; 4) Manuel Castells; 5) Maria Luiza Belloni; 
6) Boaventura de Sousa Santos; 7) Marco Silva; 8) José Manuel Costas Moran; 9) Antonio Nóvoa; 10) Nelson De Luca Pretto; 11) Raquel Goulart Barreto; 12) Jürgen Habermas; 13) Edgar Morin; 14) Mikhail Bakhtin; 15) Rena M. Palloff; 16) José Armando Valente; 17) Michel Foucault; 18) Jean Piaget; 19) Keith Pratt.

\section{0 computador como recurso didático-pedagógico}

Nesta categoria, o computador é tomado como um recurso pedagógico que pode melhorar a qualidade do processo de ensino e de aprendizagem, o aluno é visto como construtor de conhecimento e o professor como mediador entre o aluno, o computador e o saber.

Observando os autores que influenciam a formação deste discurso sobre os usos do computador, destaca-se Pierre Lévy. Ele é utilizado, principalmente, nos estudos que tratam da "Internet e Educação", para designar conceitos como "ciberespaço", "virtual e real", "ecologia cognitiva", e para explicar a relação espaço/tempo, entre outros. Pode-se afirmar que este teórico tem alicerçado o discurso pedagógico sobre os usos do computador.

Outro autor considerado referência teórica na formação do discurso pedagógico é Paulo Freire ${ }^{5}$ bastante utilizado para explicar o computador como meio pedagógico para alcançar a autonomia do aluno. Freire é citado, especialmente em textos que partem de sua definição de educação popular, na qual os homens são sujeitos de sua própria educação. Nesta lógica, destaca-se a participação e formação autônoma do aluno, ao mesmo tempo em que se defende o desenvolvimento de uma pedagogia mais crítica. Um exemplo é o estudo realizado por Vilares e Silva (2005), sobre a interatividade nos processos de comunicação em laboratórios de informática, no qual Freire é citado para fazer referência ao aprender como um processo que pode possibilitar ao aprendiz uma curiosidade que o conduza à criatividade, autonomia e participação. Nesta perspectiva, o uso do computador poderia ocasionar uma "educação mais libertadora".

Mais um autor de referência da amostra trabalhada é Jean Piaget, ${ }^{6}$ que é encontrado nos artigos que tratam do uso do computador na perspectiva da mediação pedagógica e do desenvolvimento da aprendizagem do aluno que utiliza o computador, considerando as chamadas fases de desenvolvimento.

No que se refere ao desenvolvimento cognitivo e aos processos do ensinar e do aprender, encontra-se referência aos estudos de Lev Semyonovich Vygotsky, ${ }^{7}$ que ressalta a importância do meio para o desenvolvimento da criança e para o processo de formação da mente. Os trabalhos justificam as atividades colaborativas, cooperativas e interativas a partir dos processos de ensino e aprendizagem apresentados 
por Vygostky. Como exemplo, Ramos e Quartiero (2005) trazem reflexões sobre uma metodologia baseada em problemas para o desenvolvimento de processos colaborativos suportados por ferramentas da internet em ambientes educacionais.

Com o objetivo de encontrar formulações para o uso pedagógico do computador na educação escolar, os textos analisados pelo "estado da arte" se apoiaram, especialmente, em José Manuel Costas Moran ${ }^{8}$ e José Armando Valente, ${ }^{9}$ que oferecem sugestões para o uso do computador e apostam na melhoria da aprendizagem a partir de seu uso.

Ao abordar a educação a distância (EaD), Lévy também é muito empregado, sempre no sentido de oferecer conceitos e ideias para ajudar na compreensão do processo de aprendizagem em ambientes virtuais, para a elucidação de novos tipos de linguagens e de relações no acesso, disseminação e significação dos saberes. Os conceitos deste autor são tomados para justificar a introdução das TIC em EaD, de uma forma geral, e também para fundamentar estratégias e práticas pedagógicas. Convém considerar que, quando se fala em mediação e papel do aluno e do professor em EaD, surgem autores como Marco Silva, ${ }^{10}$ Rena M. Palloff e Keith Pratt. ${ }^{11}$ Estes são citados para abordar os "novos papéis" do professor e do aluno: o professor como mediador e o aluno como construtor do conhecimento.

Como pode ser verificado, boa parte dos trabalhos analisados se baseiam no modelo construtivista para explicar a aprendizagem. Por exemplo, o estudo realizado por Matta (2002) sobre os projetos de autoria e hipermídia em rede que, para enfatizar a questão do ambiente mediador do ensino e aprendizagem de História, se baseou em teorias construtivistas, na pedagogia ativa, assim como no conhecimento dos mapas conceituais. Matta (2002, p. 8) considerou os computadores como parceiros cognitivos da mente humana, dizendo que

(...) os meios informatizados são como ambientes nos quais a mente humana encontra espaço para dialogar consigo mesma, assim como para facilitar a organização e sistematização do processo de construção do conhecimento. Os computadores são então meios nos quais se desenvolve o pensamento crítico e reflexivo, na forma concebida por Vigotsky. É possível, portanto considerar os conceitos de mediação da aprendizagem e de zona proximal nestes ambientes.

Enfim, pode-se observar que os estudos que apresentam o computador como recurso didático-pedagógico são afiliados, de forma predominante, às ideias de Piaget e, principalmente, de Vygostky, predominando um discurso do tipo construtivista. A análise do papel do computador na dimensão intrínseca aos processos de ensinar e de aprender indica o professor como mediador e facilitador do processo de aprendizagem e o aluno é visto como um sujeito autônomo, construtor de conhecimentos. 


\section{O computador como recurso político-pedagógico}

Os textos analisados abordam, também, a ligação do uso do computador na educação com aspectos que transcendem o contexto escolar. $\mathrm{O}$ alcance político do uso da tecnologia digital é tratado segundo diferentes abordagens.

Pierre Lévy tem presença marcante também nesta categoria. Mais uma vez, os conceitos de cibercultura e de ciberespaço são utilizados, mas agora para apoiar ideias ou projetos que pretendem garantir a instauração de uma sociedade democrática, através da utilização de modelos pedagógicos baseados na ecologia cognitiva ou numa inteligência coletiva.

Contudo, nesta categoria aparecem também estudos e pesquisas que buscam denunciar o processo de exclusão social proveniente da exclusão digital ou os efeitos das tecnologias digitais não para facilitar o acesso ao conhecimento (como na categoria anterior), mas para manipular as ideias ou estimular o consumo.

Dentro desta última perspectiva, entre 2006 e 2007, se inicia uma tendência a explicar os processos de dominação oculta e o poder da "rede" a partir das postulações de Michel Foucault, ${ }^{12}$ principalmente no GT de "Educação e Comunicação" da ANPEd. Este autor é utilizado para explicar as relações de poder que surgem no processo de comunicação mediado pelo computador, no qual quem domina a linguagem padrão possui maior poder de participação. Este autor também é citado no texto de Barreto (2003) sobre tecnologia e formação docente. No artigo publicado por Fischer $(2007$, p. 3) é posta a necessidade de se apoiar em Foucault para "ir além" nos estudos sobre educação e tecnologia:

(...) fazer a história de objetos técnicos, imagens, textos, sons, produtos audiovisuais, obras de arte, tomando-os por dentro de certa discursividade, estabelecendo as complexas relações entre um certo tempo, as verdades que nele se procura veicular e reafirmar, a materialidade da produção dessas verdades, as lutas em jogo e os modos de sujeição e subjetivação a elas correspondentes. Essa trama é que precisa ser descrita, quando nos debruçamos, por exemplo, sobre materiais midiáticos audiovisuais, em articulação com a vida de alunos e professores em suas práticas pedagógicas cotidianas.

As questões políticas, filosóficas e sociológicas que emergem do uso do computador na educação surgem nesta análise, quando são abordadas a $\mathrm{EaD}$, a inclusão digital, a política de formação de professores, entre outros temas. No tratamento destas questões, os autores mais citados são: Maria Luiza Belloni, ${ }^{13}$ Raquel Goulart Barreto, ${ }^{14}$ Paulo Freire e Nelson De Luca Pretto. ${ }^{15}$

Ainda, observando essa linha de investigação, nota-se a presença marcante de Edgar Morin ${ }^{16}$ quando se realiza uma discussão "filosófica". Ele é abordado nos textos a partir da teoria sistêmica da sociedade. Os autores dos textos analisados 
afirmam - apoiando-se nas ideias deste autor - que o uso da tecnologia atende às novas demandas educacionais frente à reconfiguração da sociedade da informação, ou seja, o paradigma emergente da sociedade em rede (Barreto, 2003). Morin é apropriado pelos autores na explicação das transformações do mundo contemporâneo, dos movimentos mais complexos do mundo, no qual é preciso considerar suas complementaridades, ao mesmo tempo em que seus antagonismos (Pretto, 2002).

No que se referem às políticas públicas para a implantação das TIC na educação escolar, os estudos se apoiam em autores como Marília Fonseca, ${ }^{17}$ que trata a questão do financiamento internacional e das políticas voltadas para a educação fundamental.

Manuel Castells, ${ }^{18}$ considerado o quarto cientista social mais citado no mundo, é autor principal em 15 dos textos investigados. Rüdiger (2003, p. 78-79) realiza uma análise sobre sua obra, reforçando que:

Embora Castells afirme objetivamente que "a tecnologia não determina a sociedade" e que a forma dessa última depende de um "complexo padrão interativo entre descoberta científica, inovação tecnológica e aplicação social em condições determinadas", o comentarista pode ver confirmado seu julgamento quando aquele nota, na linha seguinte, que "a tecnologia é a sociedade" (Castells, 1999, p. 25), ao penetrar por toda a extensão das relações sociais e modificar nossos sistemas de poder e padrões de experiência. Apenas em trabalhos mais recentes isso parece estar mudando.

Dessa forma, Rüdiger observa que a sociedade não pode ser representada sem suas ferramentas tecnológicas e diz que os elementos sociológicos arrolados por Castells "não deveriam nos fazer perder de vista que a convergência entre 'engenharia técnica' e 'criatividade cultural', por ele percebida, é um processo dialético" (op. cit., p. 80).

Se os discursos sobre a dimensão didático-pedagógica do computador tendem a apresentar uma versão mais "otimista", destacando os seus benefícios ou a possibilidade da apropriação deste recurso tecnológico para a melhoria da qualidade dos processos de ensinar e de aprender, os textos que tratam da dimensão político-pedagógica apresentam uma maior diversidade de abordagens. Pode-se observar a presença de textos que indicam a implantação de um modelo democrático ou popular de comunicação mediada pelo computador (baseados especialmente em Freire e Lévy), mas também aqueles que denunciam o processo de massificação e consequente isolamento humano e cultural decorrentes da instalação de uma sociedade tecnológica e tecnocrática (e, por conseguinte, de uma educação) que massifica, oprime e acentua as diferenças sociais (baseados em estudos de Barreto, Belloni, Castells, por exemplo). Por um lado, há estudos que afirmam a possibilidade de instauração de uma sociedade em rede e que transcenda os limites do 
discurso moderno (baseados em Morin, por exemplo) e, por outro, há uma denúncia dos vínculos entre os projetos educacionais de implantação da informática na educação, de educação a distância e de formação de professores, e os condicionantes econômicos impostos pelos organismos internacionais de financiamento, tendo como base os princípios de uma economia neoliberal (referenciados em Barreto e Pretto).

\section{Algumas considerações sobre o discurso tecnológico contemporâneo}

\section{A busca de solidez na orientação teórica}

Embora o "estado da arte" que serviu de base para este artigo tenha se dedicado, especificamente, aos textos sobre os usos pedagógicos do computador, acreditamos ser possível dirigir algumas considerações às tecnologias de informação e de comunicação como um todo. Ou seja, iremos ampliar as nossas reflexões para o quadro das relações entre as tecnologias e a educação, com base nas orientações teóricas identificadas a partir do "estado da arte" em questão.

Um aspecto importante a ser destacado é que, na maioria dos estudos que discursam sobre os usos do computador na educação escolar, embora os conceitos nos quais estes se baseiam apresentem relação com os temas trabalhados, nem sempre a vinculação dos referidos conceitos com o tema se apresenta de forma clara. Um exemplo são os conceitos de Lévy, fartamente citados. Estes são utilizados de forma fragmentada, sem interlocução com suas demais ideias e sem ligação com o tema principal do texto. Seus conceitos vêm mais como um apêndice do que como um fundamento que compõe o fenômeno analisado. Muito mais do que um conceito que ajuda a explicar, compreender ou intervir na prática em questão, eles servem para atestar a vinculação do texto a um referencial teórico já legitimado e aceito pela comunidade acadêmica. Ao invés de aparecer integrado ao corpo do texto e permeando a discussão realizada, as ideias de Lévy são colocadas como uma espécie de preâmbulo e, quase nunca, reaparecem para articular as análises.

Desta forma, a utilização de Lévy em boa parte dos textos analisados neste "estado da arte" parece fazer muito mais parte de um esforço para recorrer a um autor reconhecido do que de uma apropriação de suas ideias para compreensão e sistematização da discussão proposta. Além disso, os autores se apropriam de Lévy como se este fosse um estudioso da integração das tecnologias digitais à prática escolar, embora ele se dedique prioritariamente às implicações mais gerais das TIC.

Tal afirmação pode ser estendida a outros autores também bastante citados, tais como Castells ou Freire. Castells, por exemplo, é referência quase que "obrigatória" na parte introdutória dos textos que deverão fazer referência aos aspectos 
presentes na configuração social contemporânea. Mas a visão cuidadosa e fundamentada do autor sobre os possíveis riscos provenientes dos efeitos da sociedade informacional no processo de constituição das identidades autônomas é negligenciada quando se trata de abordar aspectos didático-pedagógigos em particular. $\mathrm{Na}$ verdade, Castells e Lévy são citados como se investissem nos mesmos temas ou, principalmente, como se tivessem a mesma visão sobre a sociedade em rede em sua dimensão cultural, política e econômica. Da mesma forma, a abordagem da exclusão social ou da dimensão comunicacional no uso das TIC na educação implica uma quase que mecânica alusão a Paulo Freire.

Em um decênio de estudos realizados sobre o uso do computador na educação escolar, os argumentos utilizados seguem as orientações adotadas pelos estudos referentes aos processos pedagógicos em geral. Os usos pedagógicos do computador são explicados seja sobre o prisma do desenvolvimento humano por estágios (Piaget), seja pela busca da educação popular e libertadora (Freire), seja pelo construtivismo, pela interação social, pela história, cultura e linguagem (Vygotsky). Como seria de se esperar, os estudos acerca das teorias da educação e dos processos pedagógicos com a utilização das tecnologias seguem as tendências pedagógicas "clássicas" como o construtivismo, o desenvolvimento por fases (Piaget), o instrucionismo (Skinner) e a educação popular (Paulo Freire).

Entretanto, tais estudos não estão inteiramente articulados com a discussão pedagógica da temática investigada, revelando dois tipos de apropriação distintas no que diz respeito às abordagens macroestruturais e aquelas em nível didático-pedagógico. De uma maneira bem ampla, Castells e Lévy são "adotados" para tratar da organização de uma "nova" sociedade frente às tecnologias (questões de caráter social, político, econômico e cultural) e Vygostky, Piaget e Lévy para sustentar as questões intraescolares.

O esclarecimento quanto aos pontos de convergência e, especialmente, aos de divergência entre os autores mais citados poderia ajudar a alcançar uma melhor compreensão das relações das TIC com a educação, oferecendo alternativas mais consistentes para a compreensão e a intervenção nos processos educativos. Além disso, um maior esforço no sentido de articular as dimensões macro e micro de análise também poderia auxiliar a evitar uma análise dicotômica.

\section{Entre a racionalidade instrumental e o determinismo tecnológico}

Os usos do computador na educação escolar são permeados por características deterministas e instrumentalistas como se observa no estudo realizado por Feenberg (2003). Os deterministas acreditam que a tecnologia controla a sociedade e a molda com eficiência e progresso. Acreditam que a inovação tecnológica é tão 
revolucionária que determinaria mudanças radicais na estrutura da sociedade. Os instrumentalistas têm um pensamento segundo o qual a tecnologia é uma ferramenta ou instrumento da espécie humana com o qual satisfazemos nossas necessidades (Feenberg, 2003).

Nesse sentido, é relevante considerar que há trabalhos que apresentam uma visão crítica à racionalidade instrumental como, por exemplo, Pesce (2007), que se ampara no agir comunicativo de Habermas, no discurso da linguagem de Bakhtin e na interação dialógica de Paulo Freire.

Lévy (1998), que é utilizado para explicar a técnica pelos estudiosos do "computador como recurso didático-pedagógico", afirma que ela não é boa nem má, e sim que depende do contexto de uso em que está inserida. Entretanto, sabe-se que ela é uma construção social de sujeitos situados social e historicamente (Rüdiger, 2003). Nesse sentido, Rüdiger afirma que

Lévy não deveria ser visto como o exemplo acabado de pensador tecnófilo, no sentido de, mecanicamente, reduzir a cultura à tecnologia (...) o problema com o autor, enquanto não sucumbe à propaganda new age, nos parece ser antes a falta de visão crítica e a concepção idealizada, para dizer o mínimo, do que está em jogo na formação da cibercultura. (2003, p. 63)

Caminhando na linha de tempo apresentada no estado da arte (1997-2007), observa-se uma pulverização de tendências teóricas em um movimento de "ir-evir" em torno de certos autores. Configura-se uma tendência que oscila entre: (a) acreditar que o uso do computador poderia solucionar os problemas relacionados à educação, principalmente, as questões do ensino e da aprendizagem, bem como em: (b) realizar uma negação total de uso do computador na escola. Tal tendência reforça um processo de dicotomias já presente no pensamento educacional brasileiro (Tiballi, 1998).

Essa tendência revela atos da fetichização do objeto técnico com atribuição de um poder sobrenatural ao computador, ficando preso à sua afirmação ou negação apaixonada. Heidegger (2006), ao estudar a questão da técnica, demonstra que essa visão apaixonada só reforça o aspecto de determinação instrumental da técnica.

Nesse sentido, nota-se uma tendência em louvar o uso das TIC na escola como fator de qualidade na educação, como demonstra Monteiro, Ribeiro e Struchiner (2007, p. 1042), quando dizem que "louvam-se, no discurso pedagógico, as tecnologias da informação e comunicação (TIC). Tais tecnologias destacam-se nos discursos do ensino e sobre o ensino". Os estudos atribuem sentidos diversos para a presença do computador na escola e acreditam que seu uso pode solucionar problemas 
pedagógicos que o professor encontra, ou seja, "é como se as TIC fossem dotadas de poder miraculadoso!"' (op. cit., p. 1043).

Como pode ser observado, os discursos sobre os usos do computador na educação possuem em comum a preocupação com as mudanças do mundo atual em função da presença das tecnologias. A partir deste ponto de convergência, pode-se identificar abordagens distintas. No presente artigo, buscou-se apresentar duas destas abordagens. Por um lado, uma visão instrumental, que indica a incorporação das TIC como recursos didático-pedagógicos moldados pelos sujeitos. Estes recursos, instrumentos flexíveis e maleáveis, podem ser utilizados para reproduzir as relações de dominação e de opressão numa sociedade de massas ou para transformar a educação segundo o paradigma construtivista. De outro lado, os trabalhos analisados se baseiam no determinismo tecnológico, uma visão da tecnologia como um elemento que determina a configuração social e cultural. Neste caso, a tecnologia já seria, em si mesma, um novo paradigma pedagógico e deveria ser imposta ao meio escolar como condição para uma educação em sintonia com o seu tempo.

Segundo a visão instrumental, então, os efeitos do uso da tecnologia na educação dependem da maneira como esta é apropriada pelos sujeitos: segundo um modelo instrucional e transmissivo ou segundo um modelo de aprendizagem autônoma e colaborativa. Mas a visão determinista também pode ser "otimista", ao se considerar que a tecnologia nos conduzirá a uma vida melhor, ou pode ser "pessimista", se considerarmos que a tecnologia nos conduzirá ao isolamento e ao domínio das máquinas.

Certamente, a reflexão aqui proposta não pretende direcionar a discussão do tema no sentido de adotar uma das abordagens identificadas e rejeitar a outra. Cada uma delas expressa ideias que contribuem de forma complementar para a compreensão das relações entre as tecnologias e a educação. Pretende-se, na verdade, evitar: a) tanto a tendência a realizar a fetichização das TIC, tratadas como um mero recurso no processo de ensino e aprendizagem, b) quanto a defesa de seu poder redentor de modernizar a educação (Loureiro \& Fonte, 2003).

As tecnologias são construtos sociais, ou seja, não podem ser vistas apenas como o fruto lógico de um esquema de desenvolvimento do progresso técnico. Elas são resultantes de orientações estratégicas, de escolhas deliberadas, num determinado momento dado da história e em contextos particulares. Os objetos técnicos e o meio social se relacionam segundo uma dinâmica de reciprocidade (Lima Júnior \& Pretto, 2005; Santos, 2005), não de neutralidade e muito menos de determinação unilateral. Contamos com o enfrentamento desta complexidade teórica e prática para superar as explicações simplistas, o julgamento das práticas ou a imposição de normas para professores e alunos que vivem num mundo povoado pelas tecnologias. 


\section{Notas}

1. "Qualis é uma lista de veículos utilizados para a divulgação da produção intelectual dos programas de pós-graduação stricto sensu (mestrado e doutorado), classificados quanto: à graduação stricto sensu (mestrado e doutorado); ao âmbito de circulação (Local, Nacional, Internacional) e à qualidade (A, B, C). Disponível em: <http://www.capes.gov.br/avaliacao/webqualis.html>. Acesso em: 15 jul. 2008.

2. Entre as revistas selecionadas, foram escolhidas as que possuem maior número de trabalhos publicados sobre o tema dessa pesquisa, sendo três revistas classificadas como Nacional A e três de padrão Internacional, a saber: 1) Em Aberto (ISSN: 0104-1037) - Instituto Nacional de Estudos e Pesquisas Educacionais Anísio Teixeira (Inep), periodicidade quadrimestral, classificada como Nacional A; 2) Revista Brasileira de Estudos Pedagógicos (ISSN: 0034-7183) - Instituto Nacional de Estudos e Pesquisas Educacionais Anísio Teixeira (Inep), periodicidade trimestral, classificada como Nacional A; 3) Educação \& Sociedade (ISSN: 0101-7330) - Centro de Estudos Educação e Sociedade (Cedes), periodicidade trimestral, classificada como Internacional; 4) Revista Brasileira de Educação (ISSN: 1413-2478) - Associação Nacional de Pós-Graduação e Pesquisa em Educação (ANPEd), periodicidade quadrimestral, classificada como Internacional; 5) Educação E Realidade (ISSN: 01003143) - Faculdade de Educação da Universidade Federal do Rio de Janeiro; 6) Cadernos de Pesquisa (ISSN: 0100-1574) - Fundação Carlos Chagas, periodicidade quadrimestral, classificada como Internacional.

3. O GT “Educação e Comunicação" da ANPEd disponibilizou os textos digitalizados a partir de 2000.

4. Obras mais citadas: 1) LÉVY, P. A máquina universo - criação, cognição e cultura informática. Trad. de Bruno Charles Magno. Porto Alegre: Artmed, 1998; 2) LÉVY, P. O que é o virtual? São Paulo: Editora 34, 1996; 3) LÉVY, Pierre. Cibercultura. Trad. de Carlos Irineu Costa. São Paulo: Editora 34, 1999; 4) LÉVY, P. Tecnologias da inteligência. São Paulo: Editora 34, 1995.

5. Obras mais citadas: 1) FREIRE, P. A pedagogia do oprimido. Rio de Janeiro: Paz \& Terra, 1987/1971; 2) FREIRE, P. Educação como prática de liberdade. Rio de Janeiro: Paz \& Terra, 1976; 3) FREIRE, P. Ação cultural para a liberdade. Rio de Janeiro: Paz \&e Terra, 1978; 4) FREIRE, P. Educação e mudança. Rio de Janeiro: Paz \& Terra, 1979.

6. Obras mais citadas: 1) PIAGET, J. La psychologie de l'intelligence. Paris: A. Colin, 1968; 2) PIAGET, J. Estudos sociológicos. Rio de Janeiro: Forense, 1973.

7. Obra mais citada: VYGOTSKY, L.S. A formação social da mente: o desenvolvimento dos processos psicológicos superiores. 5. ed. São Paulo: Martins Fontes, 2003.

8. Trabalho mais citado: MORAN, J.M. Educação inovadora na Sociedade da Informação. In: REUNIÃO ANUAL DE PÓS-GRADUAÇÃO E PESQUISA EM EDUCAÇÃO 25., Anais...Caxambu, 2002.

9. Trabalhos mais citados: 1) VALENTE. J.A. Diferentes usos do computador na educação. 1993. Disponível em: <http://nied.unicamp.br/publicacoes/separatas/Sep1.pdf>. Acesso em: 25 fev. 2007; 2) VALENTE, J.A. Visão analítica da informática na educação no Brasil: a questão da formação do professor. 1997. Disponível em: <http://www.professores.uff.br/hjbortol/car/library/valente.html>. Acesso em: 19 maio 2008.

10. Obras mais citadas: 1) SILVA, M. Sala de aula interativa. 2. ed. Rio de Janeiro: Quartet, 2001; 2) SILVA, M. (Org.). Educação online: teorias, práticas, legislação, formação corporativa. São Paulo: Loyola, 2003.

11. Obras mais citadas: 1) PALLOFF, R.M.; PRATT, K. Construindo comunidades de aprendizagem no ciberespaço. Trad. de Vinícius Figueira. Porto Alegre: Artmed, 2002; 2) PALLOFF, R.M.; PRATT, K. $O$ aluno virtual: um guia para trabalhar com estudantes on-line. Trad. de Vinícius Figueira. Porto Alegre: Artmed, 2004.

12. Obras mais citadas: 1) FOUCAULT, M. Vigiar e punir: nascimento da prisão. 28. ed. Petrópolis: Vozes, 1987; 2) FOUCAULT, M. A ordem do discurso. São Paulo: Loyola, 1996; 3) FOUCAULT, M. A arqueologia do saber. Rio de Janeiro: Forense Universitária, 2000. 
Tecnologia e educação: algumas considerações sobre o discurso pedagógico contemporâneo...

13. Trabalhos mais citados: 1) BELLONI, M.L. Ensaio sobre a educação a distância no Brasil. Educação $\mathcal{E}$ Sociedade, Campinas, v. 23, n. 78, p. 117-142, abr. 2002; 2) BELLONI, M.L. O que é mídia-educação. Campinas: Autores Associados, 2001;3) BELLONI, M.L. (Org.). A formação na sociedade do espetáculo. São Paulo: Loyola, 2002.

14. Trabalhos mais citados: 1) BARRETO, R.G. Tecnologias na formação de professores: o discurso do MEC. Educação \& Pesquisa, São Paulo, v. 29, n. 2, p. 271-286, jul./dez., 2003; 2) BARRETO, R.G. (Coord.). Educação e tecnologia (1996-2002). Brasília, DF: MEC/Inep, 2006. 213p. (Estado e conhecimento, 9).

15. Trabalhos mais citados: 1) PRETTO, N.L. Educação e inovação tecnológica: um olhar sobre as políticas públicas brasileiras. Revista Brasileira de Educação, Rio de Janeiro, n. 11, p. 75-85, maio/jun./jul./ ago. 1999. 2) PRETTO, N.L. Formação de professores exige rede! Revista Brasileira de Educação, Rio de Janeiro, p. 121-131, n. 20, maio/ago. 2002.

16. Obra mais citada: 1) MORIN, E. Os sete saberes necessários à educação do futuro. São Paulo: Cortez; Brasília, DF: Unesco, 2000.

17. Trabalho mais citado: FONSECA, M. O Banco Mundial e a educação brasileira: uma experiência de cooperação internacional. In: OLIVEIRA, R.P. (Org.) Política educacional: impasses e alternativas. 2. ed. São Paulo: Cortez, 1998. p. 85-122.

18. Obras mais citadas: 1) CASTELLS, M. A sociedade em rede. 9. ed. São Paulo: Paz \& Terra, 2005; 2) CASTELLS, M. A galáxia da internet. Rio de Janeiro: Zahar, 2003.

\section{Referências}

BARRETO, R.G. Tecnologias na formação de professores: o discurso do MEC. Educação \& Pesquisa, São Paulo, v. 29, n. 2, p. 271-286, jul./dez. 2003.

CASTELLS, M. A sociedade em rede. 6 ed. São Paulo: Paz \& Terra, 1999. v. 1.

DESCARTES, R. Discurso do método. 4. ed. São Paulo: Nova Cultura, 1987. v. 1, p. 23-71. (Os pensadores)

FEENBERG, A. O que é a filosofia da tecnologia? Conferência pronunciada para os estudantes universitários de Komaba, junho de 2003, sob o título de "What is philosophy of technology?". Tradução de Agustín Apaza, com revisão de Newton Ramos-deOliveira. Disponível em: <http://www.sfu.ca/ andrewf/oquee.htm>. Acesso em: 5 ago. 2007.

FISCHER, R.M.B. Mídia, máquinas de imagens e práticas pedagógicas. Revista Brasileira de Educação, Rio de Janeiro, v. 12, n. 35, p. 290-299, maio/ago. 2007.

FRANCO, M.L.P.B. Análise de conteúdo. 2. ed. Brasília, DF: Líber Livro, 2005.

HEIDEGGER, M. A questão da técnica. In: HEIDEGGER, M. Ensaios e conferências. Petrópolis: Vozes, 2006. p. 11-38.

LÉVY, P. A máquina universo: criação, cognição e cultura informática. Trad. de Bruno Charles Magno. Porto Alegre: Artmed, 1998. 
LIMA JÚNIOR, A.S.; PRETTO, N.L. Desafios para o currículo a partir das tecnologias contemporâneas. In: PRETTO, N.L. (Org.). Tecnologia e novas educações. Salvador: Edufba, 2005. p. 203-213.

LOUREIRO, R.; FONTE, S.S.D. Indústria cultural e a educação em "tempos pós-modernos". São Paulo: Papirus, 2003.

MATTA, A.E.R. Projetos de autoria hipermídia em rede: ambiente mediador para o ensino-aprendizagem de História. In: REUNIÃO ANUAL DA ASSOCIAÇÃO NACIONAL DE PÓS-GRADUAÇÃO E PESQUISA EM EDUCAÇÃO , 25., 2002. Anais... Caxambu: ANPEd, 2002.

MONTEIRO, D.M.; RIBEIRO, V.M.B.; STRUCHINER, M. As tecnologias da informação e da comunicação nas práticas educativas: espaços de interação?; estudo de um fórum virtual. Educação \& Sociedade, Campinas, v. 28, n. 101, p. 1435-1454, 2007.

PAPADOUDI, H. De l'alliance entre éducation et informatique. Pratiques de Formation Analyses, Paris, n. 35, p. 13-14, 1998.

PEIXOTO, J. Metáforas e imagens dos formadores de professores na área da informática aplicada à educação. Educação \& Sociedade, Campinas, v. 28, n. 101, p. 14791500, 2007.

PEIXOTO, J. A inovação pedagógica como meta dos dispositivos de formação a distância. EccoS, São Paulo, v. 10, n. 1, p. 39-54, jan./jun. 2008a.

PEIXOTO, J. Culturas digitais juvenis e as funções das tecnologias de informação e de comunicação na escola. In: GALVÃO, A.C.T.; SANTOS, G.L. Educação: tendências e desafios de um campo em movimento. Brasília, DF: Líber Livro; ANPEd, 2008b. p. 27-43.

PESCE, L. Educação à distância e formação de educadores: a contribuição dos desenhos didáticos dialógicos. In: REUNIÃO ANUAL DA ASSOCIAÇÃO NACIONAL DE PÓS-GRADUAÇÃO E PESQUISA EM EDUCAÇÃO, 30., 2007, Anais...Caxambu: ANPEd, 2007.

PRETTO, N.L. Formação de professores exige rede! Revista Brasileira de Educação, Rio de Janeiro, n. 20, p. 121-13, maio/ago. 2002.

RAMOS, D.K.; QUARTIERO, E.M. Colaboração, problematização e redes: um estudo com alunos do ensino fundamental. In: REUNIÃO ANUAL DA ASSOCIAÇÃO NACIONAL DE PÓS-GRADUAÇÃO E PESQUISA EM EDUCAÇÃO, 28., 2005, Anais... Caxambu: ANPEd, 2005.

RÜDIGER, F.R. Introdução às teorias da cibercultura: perspectivas do pensamento tecnológico contemporâneo. Porto Alegre: Sulina, 2003. 
SANCHO, J.M. De tecnologias da informação e comunicação a recursos educativos. In: SANCHO, J. M. et al. Tecnologias para transformar a educação. Porto Alegre: ArtMed, 2006. p. 15-41.

SANTOS, E.O. Educação on-line: a dinâmica sociotécnica para além da educação a distância. In: PRETTO, N.L. (Org.). Tecnologia e novas educações. Salvador: Edufba, 2005. p. 193-202.

TIBALLI, E.F.A. Fracasso escolar: a constituição sociológica de um discurso. 1998. Tese (Doutorado em Educação) - Pontifícia Universidade Católica de São Paulo, São Paulo.

VILARES, A.R.; SILVA, M. Interatividade como perspectiva comunicacional no laboratório de informática: um desafio ao professor. In: REUNIÃO ANUAL DA ASSOCIAÇÃO NACIONAL DE PÓS-GRADUAÇÃO E PESQUISA EM EDUCAÇÃO, 28., 2005, Anais...Caxambu: ANPEd, 2005.

Recebido em 22 de fevereiro de 2010.

Aprovado em 2 de dezembro de 2010. 